\title{
Existence and behaviour of parameter classes of solutions of a system of quasilinear differential equations
}

\section{Alma OMERSPAHIĆ}

\section{ABSTRACT.}

The paper presents some results on the existence and behaviour of parameter classes of solutions for system of quasilinear differential equations. Behaviour of integral curves in neighborhood of an arbitrary or a certain curve is considered. The obtained results contain the answer to the question on stability as well as approximation of solutions whose existence is established. The errors of the approximation are defined by the functions that can be sufficiently small. To obtain our main results, the theory of qualitative analysis of differential equations and topological retraction method are used.

\section{REFERENCES}

[1] Omerspahić, A., Retraction method in the qualitative analysis of the solutions of the quasilinear second order differential equation In: Applied Mathematics and Computing (Rogina, M. et al., Eds.), Department of Mathematics, University of Zagreb, Zagreb, (2001), 165-173

[2] Omerspahić, A., Existence and behavior of solutions of a system of quasilinear differential equations, Creative Mathematics and Informatics, 17 (2008), No. 3, 487-492

[3] Omerspahić, A. and Vrdoljak, B., On parameter classes of solutions for system of quasilinear differential equations, in Proceedings of the Conference on Applied Mathematics and Scientific Computing, Brijuni, Croatia, June 13-19 (Drmač, Z. et al., Eds.), Springer, Dordreht, (2005), 263-272

[4] Sabin, G. C. and Summers, D., Caos an a periodically forced predator-prey ecosystem model, Mathematical Biosciences, 113 (1993), 91-113

[5] Volterra, V., Variazione e fluttazini del numero d'individui in specie animali conviventi, Mem. Accad. Nazionale Lincei, 62 (1926), 31-113

[6] Vrdoljak, B. and Omerspahić, A., Qualitative analysis of some solutions of quasilinear system of differential equations. In: Applied Mathematics and Scientific Computing (Dubrovnik, 2001) (Drmač, Z. et al., Eds.), Kluwer/Plenum, New York, 2003, 323-332

[7] Vrdoljak, B. and Omerspahić, A., Existence and approximation of solutions of a system of differential equations of Volterra type, Mathematical Communications, 9 (2004), No. 2, 125-139

[8] Wažewski, T., Sur un principe topologique de l'examen de l'allure asymptotique des integrales des equations differentielles ordinaires, Ann. Soc. Polon. Math., 20 (1947), 279-313

UNIVERSITY OF SARAJEVO

MECHANICAL ENGINEERING FACULTY

Vilsonovo Setaliste 9, 71000 SARAJEVo, Bosnia AND HERZEgovina

E-mail address: alma.omerspahic@mef. unsa.ba 